\title{
Postnatal Histomorphological Studies on the Gall Bladder of Guinea Pig (Cavia porcellus)
}

\author{
S. Rajathi ${ }^{1 *}$, Geetha Ramesh ${ }^{2}$, T.A. Kannan ${ }^{3}$, S. Hemalatha ${ }^{3}$ and S. Paramasivan ${ }^{4}$ \\ ${ }^{1}$ Veterinary College and Resaerch Institute, Tirunelveli, Tamil Nadu, INDIA \\ ${ }^{2}$ Director of Distance Education, Chennai, Tamil Nadu, INDIA \\ ${ }^{3}$ Madras Veterinary College, Chennai, Tamil Nadu, INDIA \\ ${ }^{4}$ Veterinary College and Research Institute, Orathandu, Tamil Nadu, INDIA \\ "Corresponding author: S Rajathi; E-mail: rajathis9936@gmail.com
}

Received: 17 June, 2021

Revised: 16 July, 2021

Accepted: 18 July, 2021

\begin{abstract}
Gall bladder is a small pouch found attached to the liver and stores bile. A total of 24 guinea pigs of four different postnatal ages with six animals each were collected from the Department of Laboratory Animal Medicine as per the Ethical committee approval. Gall bladder were dissected, fixed and processed for paraffin embedding. Sections of 4-5 $\mu \mathrm{m}$ thickness were cut and used for the routine and special histological staining techniques. The wall of the gall bladder consisted of tunica mucosa, submucosa, muscularis and serosa in all the postnatal ages. The tunica mucosa of gall bladder consisted of irregular folds with primary, secondary and tertiary folds. All the folds were visible in the gall bladder of postnatal ages with the folding increased as age increased. Guinea pigs of 0-2 weeks of age showed only primary folds of less height. The tunica mucosa consisted of lining epithelium and lamina propria. Mucularis mucosa was not observed in all ages. Lamina propria and submucosa formed a continuous layer. The lining epithelium was simple tall columnar epithelium with irregular microvilli at the luminal border. Lamina propria - submucosa consisted of loose of connective tissue with collagen, reticular fibres, fibroblasts, lymphocytes and blood vessels. Tunica muscularis was a fibromuscular coat, consisted of loose arrangement of smooth muscular layers in longitudinal and circular fashion. Tunica serosa covered the external surface of the gall bladder in all ages and consisted of loose connective layer which was upcovered by a single layer of mesothelium.
\end{abstract}

\section{HIGHLIGHTS}

(0 Guinea pigs of group I showed only primary folds.

(0 Goblets cells were not observed in epithelium

(- Muscularis mucosa and glands were not observed.

Keywords: Microanatomy, Postnatal Development, Gall bladder, Guinea pig

Guinea pigs have been commonly kept as pets, as well as used extensively in medical research with the first documented experiments performed on guinea pigs dated back to 1780 . Their use in research was at peak in the 1960s and was declined later due to the declining nature of population of guinea pigs in research. But now large rodents like guinea pigs were used as best experimental animals with their large body weight, easiness of handling and its rapid adaptation (Witkowska et al., 2017). Gall bladder is a small pear shaped organ found attached to the gall bladder fossa of liver and stores bile in animals (Srivastava and Khan, 2017). The understanding of the anatomical variation and development of rodent gall bladder is essential to avoid any critical complications while performing experimental surgery on these organs.

How to cite this article: Rajathi, S., Ramesh, G., Kannan, T.A., Hemalatha S. and Paramasivan, S. (2021). Postnatal Histomorphological Studies on the Gall Bladder of Guinea Pig (Cavia porcellus). J. Anim. Res., 11(04): 695-699.

Source of Support: None; Conflict of Interest: None क क 
Biliary tract disorders like distended gall bladder, gall bladder sludge and choleliathiasis were diagnosed by using ultrasonagraphy in dogs by knowing the anatomy of gall bladder (Lakshmi et al., 2018).

To evaluate the pathologic and clinical reactions, it is essential to understand the normal structure of the organ. Hence, a thorough knowledge on the histology of the gall bladder is necessary for the proper diagnosis and treatment of ailments. The experimental animals like guinea pigs, mouse, rats, pigs and monkeys play an important role in human medicine since the anatomical structure of the organs of experimental animals is similar to anatomical structure of the organs of humans (Al-Sharoot, 2014). Since, there is paucity of literature in the structure of gall bladder of guinea pig, the present research work is carried out with the objective to study the histomorphological development of gall bladder in postnatal age groups of Guinea pig.

\section{MATERIALS AND METHODS}

The guinea pigs were collected from the Department of Laboratory Animal Medicine, Madhavaram Milk Colony, Chennai as per the Ethical Committee approval (Lr. No. 1467/DFAB/IAEC/2018 dated 13.07.2018). Gall bladder was collected from the six number of animals from each groups mentioned below:

Table 1: Group wise distribution of animals

\begin{tabular}{llll}
\hline Sl. No. & Group & Age & $\begin{array}{l}\text { No. of Animals } \\
\text { (Male + Female) }\end{array}$ \\
\hline 1 & I & $0-2$ weeks & $6(3+3)$ \\
2 & II & $2-8$ weeks & $6(3+3)$ \\
3 & III & $8-16$ weeks & $6(3+3)$ \\
4 & IV & $16-32$ weeks & $6(3+3)$ \\
\hline
\end{tabular}

The animals were anesthetized using carbon-di-oxide asphyxiation and dissected. Gall bladder was located in the abdominal cavity proximity to liver and intestines. The gall bladder of guinea pigs of postnatal age groups was collected. They were washed in the normal saline and fixed either in $10 \%$ neutral buffered formalin or Zenker's fluid or Bouin's fluid for histological studies. Then the tissues were dehydrated in the ascending grades of the alcohol cleared in xylene and embedded in paraffin (58$60^{\circ} \mathrm{C}$ ). Sections of $4-5 \mu \mathrm{m}$ thickness were cut and used for the routine and special histological staining techniques. The following histological techniques were applied for the study.

1. Standard Haemotoxylin and Eosin method for paraffin sections (Bancroft and Stevens, 1996) for routine histological observations.

2. Van Gieson's technique for collagen fibres (Luna, 1968).

3. Masson's Trichrome for connective tissue fibres (Luna, 1968).

4. Weigert's method for elastic fibres (Humason, 1979).

5. Gomori's silver method for reticulum (Luna, 1968).

6. Bieschowsky's method for axis cylinder and dendrites (Luna, 1968).

\section{RESULTS AND DISCUSSION}

The gall bladder of male and female guinea pigs had almost same structure without any significant differences. The wall of the gall bladder consisted of tunica mucosa, submucosa, muscularis and serosa (Fig. 1) in all the postnatal ages as reported by Yamada (1955) in hamster and Mobini (2012) in avian gall bladder but they were not discussed about the tunica submucosa.

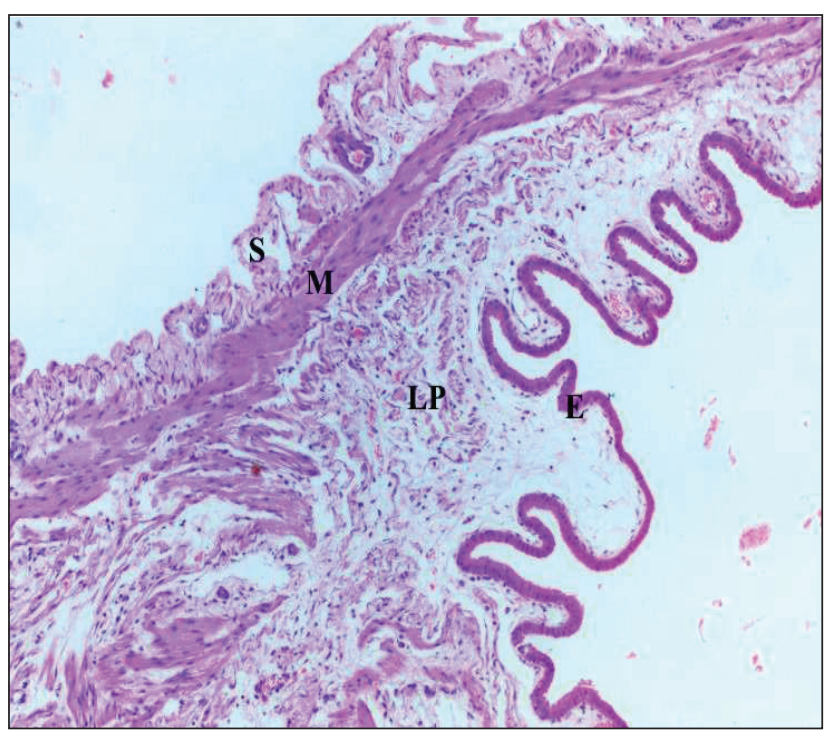

Fig. 1: Photomicrograph of two week-old guinea pig gall bladder showing epithelium (E), lamina propria (LP), muscularis (M) and serosa $(\mathrm{S})(\mathrm{H} \& \mathrm{E} \times 400)$ 


\section{Tunica mucosa}

The tunica mucosa of gall bladder consisted of irregular folds with primary, secondary and tertiary folds (Fig. 2). All the folds were visible in the gall bladder of postnatal ages with the folding increased as age increased and maximum fold was observed from 16-32 weeks of age (Fig. 2).

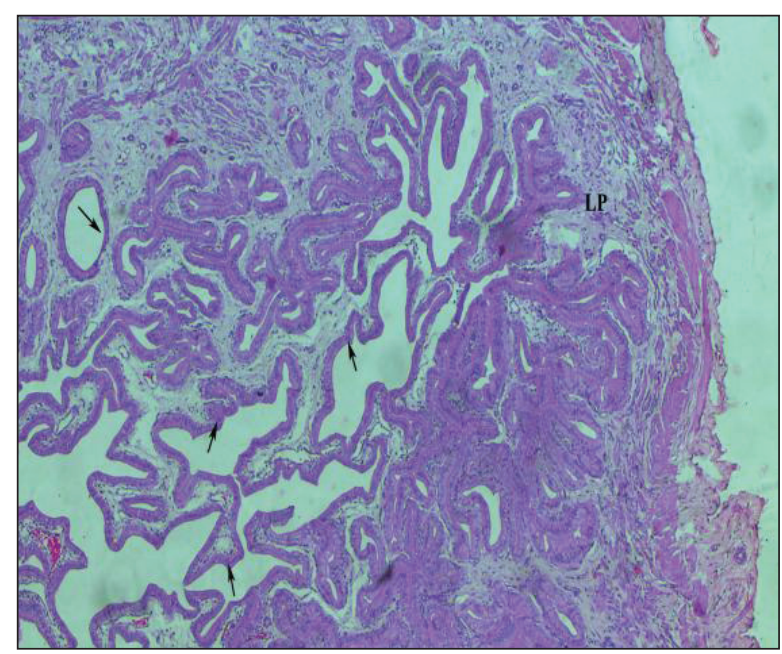

Fig. 2: Photomicrograph of 20 week-old guinea pig gall bladder showing epithelium (arrow) and lamina propria (LP) (H\&E $\times$ 400)

Guinea pigs of $0-2$ weeks of age showed only primary folds of less height (Fig. 3).

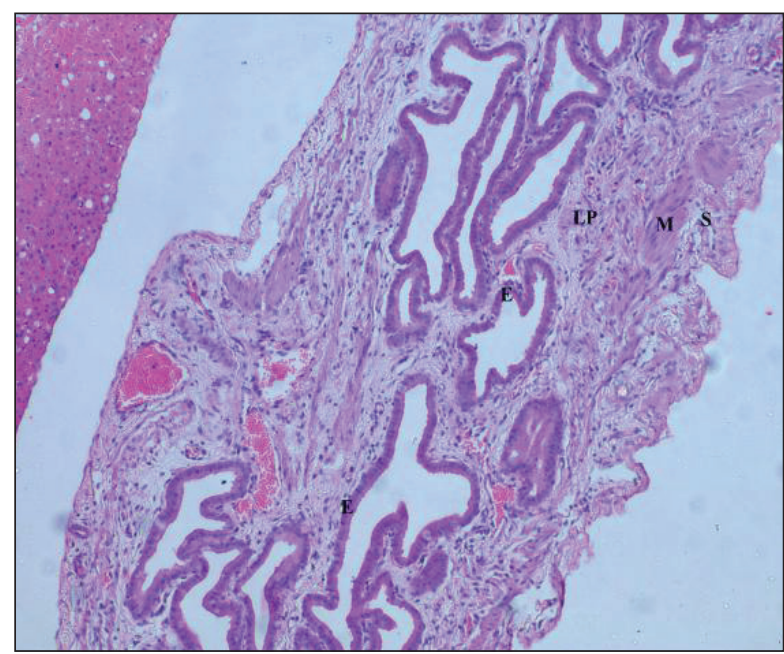

Fig. 3: Photomicrograph of 10 day-old guinea pig gall bladder showing primary epithelium folds E - Epithelium LP - Lamina propria M - Muscularis S - Serosa $(H \& E \times 100)$
The tunica mucosa consisted of lining epithelium and lamina propria in all postnatal ages as stated by Yamada (1955) in hamster gall bladder, Hatami-Monazah and Abdallah (1978) in goat gall bladder, Mobini (2012) in avian gall bladder. Similar to the present observation Yamada (1955) in hamster gall bladder also did not find goblet cells in the lining epithelium whereas, Bamaniya et al. (2016) in Marwari goat gall bladder and Mobini (2013) in quail found goblet cells in the lining epithelium.

Muscularis mucosa was not observed in all ages. So, Lamina propria and submucosa formed a continuous layer as recorded by Mobini (2012) in avian gall bladder. The lining epithelium was simple tall columnar epithelium with irregular microvilli at the luminal border (Fig. 4).

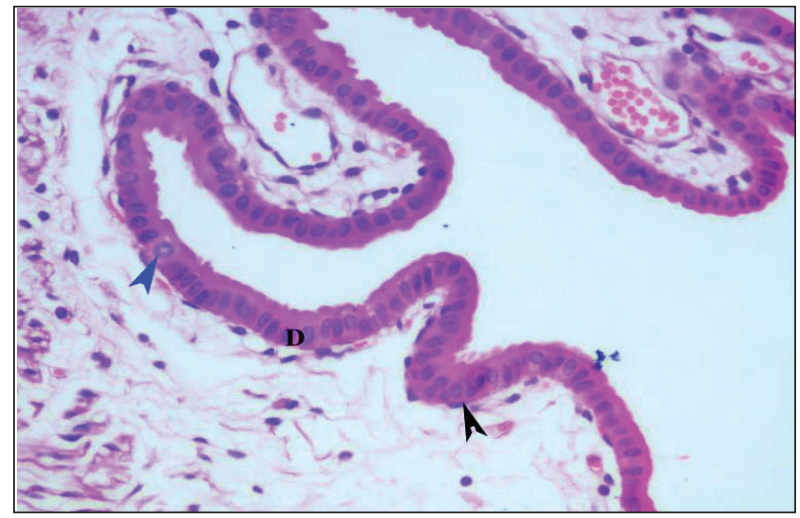

Fig. 4: Photomicrograph of 30 week-old guinea pig gall bladder showing dark (D) and light cells (blue arrow) and some basal cells (black arrow) towards the basement membrane $(\mathrm{H} \& \mathrm{E} \times$ 400)

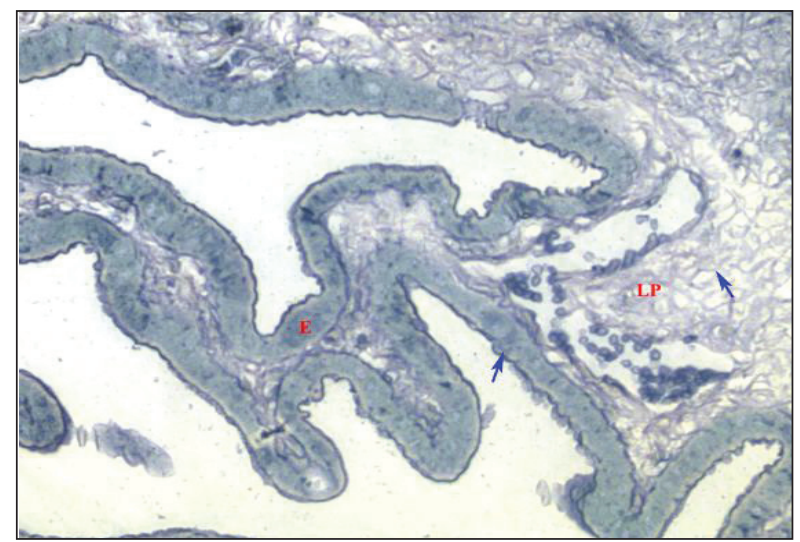

Fig. 5: Photomicrograph of two week-old guinea pig gall bladder showing reticular fibres (arrow) in the apical part of epithelium (E) and lamina propria (LP) (Gomori's Method $\times 400$ ) 
Reticular fibres were found in the apical border of the lining epithelium and were not observed in the basement membrane (Fig. 5) in all the age groups of the present study as stated by Mobini (2012) in avian gall bladder. The lining epithelium of gall bladder had dark and light cells and some basal cells towards the basement membrane (Fig. 4). Goblet cells were not observed in the lining epithelium in the present study of all the age groups. Similar results were also recorded in Japanese quail (Mobini, 2013).

Lamina propria-submucosa consisted of loose of connective tissue with collagen, reticular fibres, fibroblasts, lymphocytes and blood vessels as stated by Mobini (2012) in avian gall bladder. Cask-like cells, crayon-like cells and glands in the lamina propria were not observed in the present study but were seen in the hamster gall bladder (Yamada, 1955). Mucous glands were seen in subepithelial layer of goat gall bladder (Hatami-Monazah and Abdallah, 1978) which was not observed in the present study. This may be due to species differences.

\section{Tunica muscularis}

Tunica muscularis was a fibromuscular coat, consisted of loose arrangement of smooth muscular layers in longitudinal and circular fashion whereas Yamada (1955) in addition to the present finding also observed transverse and oblique direction of muscle fibres in hamster gall bladder. Similar results were also reported by HatamiMonazah and Abdallah (1978) in goat gall bladder, Cai and Gabella (1984) in guinea pig gall bladder and Maya et al. (2012) and Mobini (2012) in avian gall bladder. Dense connective tissue separated the muscular bundles (Fig. 6) with the occurrence of blood vessels.

\section{Tunica serosa}

Tunica serosa covered the external surface of the gall bladder in all ages and consisted of loose connective layer which was upcovered by a single layer of mesothelium (Fig. 6) as recorded by Cai and Gabella (1984) in guinea pig. The serosa was thicker in some areas and thinner in some areas. The loose connective tissue of the tunica serosa was found many blood vessels as reported by Yamada (1955) in hamster gall bladder and Maya et al. (2012) in avian gall bladder. Elastic fibres were also observed in the wall of the blood vessels. The gall bladder of 16-32 weeks of ages showed the presence the large blood vessels in the tunica serosa. Glands in serosa was absent in the avian species (Maya et al., 2012) similar to the present observation.

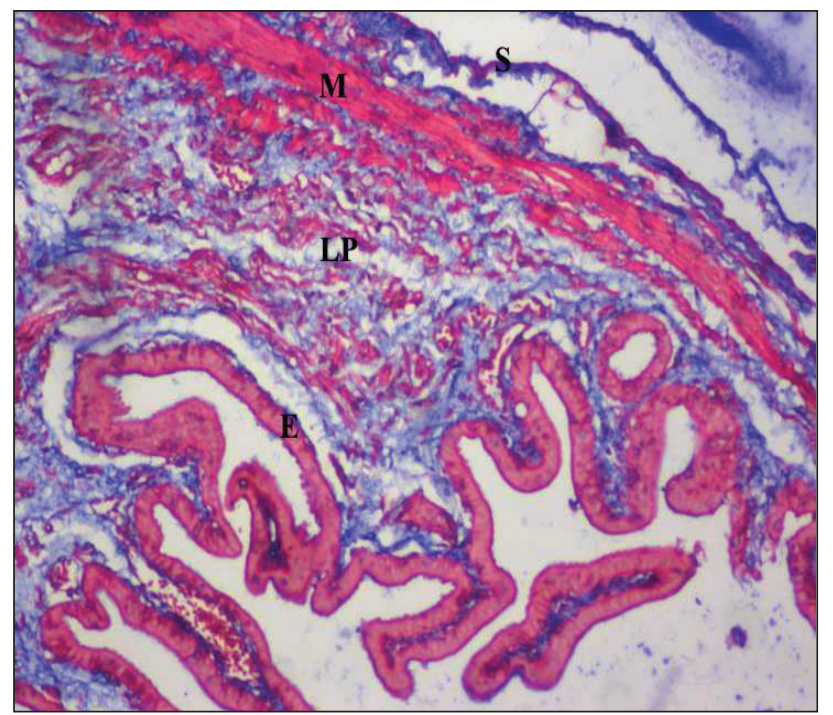

Fig. 6: Photomicrograph of 10 day-old guinea pig gall bladder showing blue collagen fibres in the lamina propria (LP) and serosa (S) and muscle fibres in Muscularis(M) E - Epithelium (Masson's Trichrome $\times 100$ )

\section{CONCLUSION}

The wall of the gall bladder consisted of tunica mucosa, submucosa, muscularis and serosa in all the postnatal age groups. Tunica mucosa was lined by simple tall columnar epithelium with irregular microvilli at luminal border and was thrown into primary, secondary and tertiary folds. Muscularis mucosa and glands in lamina propria were not observed in the present study. Tunica muscularis consisted of loose arrangement of smooth muscle fibres in longitudinal and circular fashion in all the postnatal age groups. The cystic duct consisted of tunica mucosa, submucosa, muscularis and serosa in all the postnatal ages. The bile duct opened in the duodenal papilla of duodenum with an angle of $240-300^{\circ}$ degrees.

\section{ACKNOWLEDGEMENTS}

The authors acknowledge the Dean, Madras Veterinary College, TANUVAS, Chennai for providing necessary support to carry out this project. 


\section{REFERENCES}

Al-Sharoot, H.A. 2014. Morphological and histological study of the kidney in guinea pig. Inter. J. Recent Sci. Res., 5(11): 1973-76.

Bamaniya, M.K., Barolia,Y., Mathur, R., Shende, K. and Joshi, S. 2016. Morphological and histological study on gall bladder of Marwari goat. Inter. J. Sci. Environ. Tech., 5(6): $3713-3718$.

Bancroft, J.D. and Stevens, A. 1996. Theory and Practice of Histological Techniques. $4^{\text {th }}$ Edition, Churchill Livingstone, New York.

Cai, W.Q. and Gabella. G. 1984. Catecholamine-containing cells in the nerve plexus of the guinea pig gall bladder. Acta Anat. (Basel)., 119(1): 10-17.

Hatami-Monazah, H. and Abdallah, O. 1978. Study on the morphology of the gall-bladder of the goat. Acta Anat. (Basel)., 100(2): 203-209.

Humason, G.L. 1979. Animal Tissue Techniques. $4^{\text {th }}$ Edition, W.H. Freeman, San Francisco.

Lakshmi, K., Padmaja, K., Nagaraj, P., Reddy, A. and Prakash, M. 2018. Ultrasonographic diagnosis of biliary tract disorders in dogs. Inter. J. Livestock Res., 8(10): 281-286.

Luna, L. G. 1968. Manual of histologic staining methods of the armed forces institute of pathology, $3^{\text {rd }}$ Edition, McGrawHill, New York.
Maya, S., Lucy, K.M., Indu, V.R., Karthiayini, K. and Asha, A. 2012. Microanatomical observations on the gall bladder in Kuttanad duck (Anasplatyrynchos domesticus). Sciences Index Copernicus Inter., 29: 57-59.

Mobini, B. 2012. Microscopic study of the gall bladder of the Chukar Partidge (Alectoris chukar). Bulg. J. Vety. Med., 15(2): 73-78.

Mobini, B. 2013. Histological study of the gall bladder of the common quail (Coturnix coturnix). Veterinarni Medicina., 59(5): 261-264.

Rowlands, I.W. and Weir, B.J. 1974. The biology of hystricomorph rodents. Q. Rev. Biol., 51(1): 156.

Srivastava, D.S. and Khan, D.A.Z. 2019. Morphology of gall bladder- A cadaveric study. J. Curr. Med. Res. Opinion, 2(10): 293-298.

Tortora, G.J. and Derrickson, B.H. 2008. Principles of Anatomy and Physiology. $12^{\text {th }}$ edition. John Wiley \& Sons.

Witkowska, A., Price, J., Hughes, C., Smith, D. and White, K. 2017. The Effects of Diet on Anatomy, Physiology and Health in the Guinea Pig. J. Anim. Health Behav. Sci., 1: 103.

Yamada, E. 1955. The fine structure of the gall bladder epithelium of the mouse. J. Biophys. Biochem. Cytol., 1(5): 445-458. 
